\title{
Níveis de Concentrado em Dietas de Novilhos Mestiços F1 Simental x Nelore. 1. Consumo e Digestibilidades ${ }^{1}$
}

\author{
Gilson Camargo Tibo ${ }^{2}$, Sebastião de Campos Valadares Filho $^{3}$, Rilene Ferreira Diniz Valadares ${ }^{3}$, \\ José Fernando Coelho da Silva ${ }^{3}$, Paulo Roberto Cecon ${ }^{3}$, Maria Ignez Leão ${ }^{3}$, Rosane Barros da Silva ${ }^{4}$
}

\begin{abstract}
RESUMO - Realizou-se um experimento com o objetivo de avaliar os efeitos de níveis de concentrado nas rações sobre o consumo e as digestibilidades aparentes totais e parciais de matéria seca (MS), matéria orgânica (MO), proteína bruta (PB), extrato etéreo (EE), carboidratos totais (CHO), fibra em detergente neutro (FDN) e carboidratos não-estruturais (CNE). Foram estudados os efeitos das coletas de amostras, realizadas durante o dia e a noite, sobre as digestibilidades aparentes totais e parciais da MS e MO. Utilizaramse cinco novilhos $\mathrm{F}_{1}$ Simental x Nelore, não-castrados, fistulados no rúmen, abomaso e íleo, alimentados à vontade com dietas que continham 25,0; 37,5; 50,0; 62,5; e 75,0\% de concentrado e distribuídos em delineamento quadrado latino 5 x 5 . Foram utilizados os fenos dos capins braquiária (Brachiaria decumbens, Stapf) e coast-cross (Cynodon dactylon), em proporções iguais. O óxido crômico foi usado como indicador para a determinação dos fluxos de digestas e excreção fecal. A adição de quantidades crescentes de concentrado à dieta produziu aumentos lineares nos consumos de MS, MO, PB, EE, CHO, CNE e NDT e redução no consumo de FDN. As digestibilidades aparentes totais de MS, MO, PB, EE, CHO e CNE cresceram linearmente com o aumento dos níveis de concentrado da dieta. As digestibilidades aparentes da FDN no rúmen e pós-rúmen não foram influenciadas pelos níveis de concentrado. A redução nos níveis de FDN das rações resultou em aumentos lineares do NDT e da digestibilidade aparente total da MS. Amostras representativas de fezes e digestas de abomaso e íleo podem ser obtidas utilizando-se somente coletas durante o dia.
\end{abstract}

Palavras-chave: bovinos, concentrado, consumo, digestibilidade

\section{Concentrate Levels in the Crossbred F1 Simental x Nellore Bulls Diets. 1. Intake and Digestibilities}

\begin{abstract}
An experiment was carried out to evaluate the dietary concentrate levels on the intake, total and partial apparent digestibilities of dry matter (DM), organic matter (OM), crude protein (CP), ether extract (EE), total carbohydrates (CHO), neutral detergent fiber (NDF) and non structural carbohydrates (NEC). The effects of samples collections, realized on the day or the night, on the total and partial apparent digestibilities of DM and OM, were studied. Five $\mathrm{F}_{1}$ Simental $\mathrm{x}$ Nellore bulls fistulated in the rumen, abomasum and ileum, full fed diets with 25.0, 37.5, 50.0, 62.5, and 75.0\% of concentrate and allotted to $5 \times 5$ Latin square, were used. The hays of brachiaria (Brachiaria decumbens, Stapf) and coast-cross grasses (Cynodon dactylon) were used in the same proportions. The chromic oxide was used as indicator to determine the digesta flows and fecal excretion. The addition of increasing amounts of concentrate to the diet resulted in linear increases in the DM, OM, CP, EE, CHO, NEC and TDN intakes and reduction in the NDF intake. The total apparent digestibilities of DM, OM, CP, EE, CHO, NEC and TDN linearly increased with the increasing concentrate levels. The concentrate levels did not influence the NDF apparent digestibilities in the rumen and post-rumen. The reduction in the dietary NDF levels resulted in TDN linear increases and DM total apparent digestibility. Feces and abomasum and ileum digesta representative samples can be obtained using collections only during the day.
\end{abstract}

Key Words: bovines, concentrate, intake, digestibility

\section{Introdução}

A ingestão de matéria seca é o fator determinativo na performance animal, poisé o primeiro ponto determinante do ingresso de nutrientes, principalmente energia e proteína, necessários ao atendimento das exigências de mantença e produção animal (NOLLER et al., 1996).
O consumo é função do animal (peso vivo, nível de produção, variação no peso vivo, estádio de lactação, estado fisiológico, tamanho, entre outros), do alimento (FDN efetiva, volume, capacidade de enchimento, densidade energética, necessidade de mastigação, entre outros), das condições de alimentação (disponibilidade de alimento, espaço no cocho,

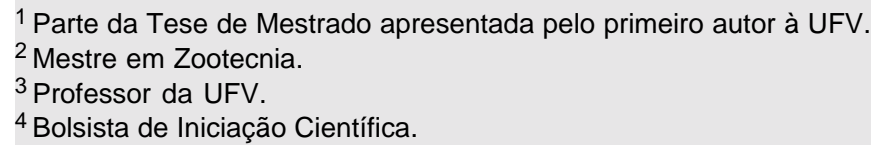


tempo de acesso ao alimento e freqüência de alimentação) e das condições climáticas (MERTENS, 1992).

As estimativas do consumo de alimentos em bovinos de corte são vitais para a predição do ganho de peso, assim como para o estabelecimento dos requerimentos nutricionais dos animais, necessários à formulação das dietas (NATIONAL RESEARCH COUNCIL - NRC, 1996).

Segundo THIAGO e GILL (1990), quando forragens com baixas taxas de digestão são fornecidas aos animais, o fator limitante para o consumo é a capacidade física do rúmen, por outro lado, quando forragens com altas taxas de digestão são ingeridas, a liberação de nutrientes no rúmen é que limita o consumo.

Existe alta relação entre o consumo voluntário de MS e o teor de FDN do alimento e da dieta, porque a fermentação e a passagem da FDN pelo rúmenretículo são mais lentas que outros constituintes dietéticos, tendo grande efeito no enchimento e no tempo de permanência nestes compartimentos, comparado com outros componentes não-fibrosos do alimento (Van Soest, 1965; Meissner e Paulsmeier, 1995, citados por SIGNORETTI, 1998).

HOOVER (1986), em trabalho de revisão, relatou que tem sido demonstrada alta correlação entre o consumo de MS e o teor de FDN da forragem e dietas contendo menos de $65 \%$ de concentrados, ou mais de $32 \%$ de FDN, têm o consumo definido pelo efeito do enchimento. WALDO (1986), entretanto, ponderou que o ponto de transição entre os mecanismos reguladores de consumo não é fixo para uma diversidade de situações.

ARAÚJO et al. (1998), estudando várias proporções de volumoso e concentrado, constataram que a adição de doses crescentes de volumosos (10 a 90\%) à dieta de bezerros Holandeses provocou aumento linear no consumo de FDN e efeito quadrático sobre os consumos de MS e MO, expressos em kg/dia, cujo ponto de máximo foi estimado com $33,3 \%$ de volumosos para ambos os nutrientes. No entanto, CARVALHO et al. (1997a) não encontraram efeito da adição de concentrados à dieta de zebuínos adultos sobre o consumo de MS ou MO, embora tenha sido verificado decréscimo linear no consumo de FDN, devido à redução progressiva na proporção de volumosos até o limite de $30 \%$ da ração.

O efeito da relação volumoso:concentrado sobre o coeficiente de digestibilidade da MS foi observado por GONÇALVES (1988), que encontrou aumento para a digestibilidade da MS, com variação do nível de concentrado de 20 para $60 \%$ da dieta. Utilizando proporções de 40 e $60 \%$ de concentrado e feno de capim-gordura, VALADARES FILHO (1985) observou coeficiente de digestibilidade da MS maior para o nível de $60 \%$ de concentrado. Segundo esse autor, isso ocorreu devido à maior concentração de carboidratos não-estruturais e à menor concentração de carboidratos estruturais, uma vez que os carboidratos não-estruturais apresentaram digestibilidade aparente acima de $90 \%$ e os carboidratos estruturais, próximo de $50 \%$, o que refletiu na maior digestão da MS, quando se utilizou o nível de $60 \%$ de concentrado.

O presente trabalho foi conduzido com os objetivos de avaliar o efeito de cinco níveis de concentrado sobre os consumos e as digestibilidades aparentes totais e parciais de matéria seca (MS), matéria orgânica (MO), proteína bruta (PB), extrato etéreo (EE), carboidratos totais $(\mathrm{CHO})$, fibra em detergente neutro (FDN) e carboidratos não-estruturais (CNE) e estimar NDT a partir dos teores de FDN das dietas. Avaliaram-se, também, diferenças nas digestibilidades da MS e MO obtidas com amostras coletadas durante o dia e a noite, utilizando-se novilhos mestiços $F_{1}$ Simental x Nelore.

\section{Material e Métodos}

O experimento foi conduzido nas dependências do Departamento de Zootecnia (DZO) do Centro de Ciências Agrárias da Universidade Federal de Viçosa, em Viçosa, MG.

A cidade de Viçosa está localizada na Zona da Mata do Estado de Minas Gerais, a $657 \mathrm{~m}$ de altitude, $20^{\circ} 45^{\prime} 20^{\prime}$ ' de latitude sul e 42 $52^{\prime} 40$ " de longitude oeste. Apresenta temperaturas médias anuais com máximas e mínimas de 26,1 e $14^{\circ} \mathrm{C}$, respectivamente, e precipitação pluviométrica de $1341 \mathrm{~mm}$ anuais (UNIVERSIDADE FEDERAL DE VIÇOSA - UFV, 1994).

Foram utilizados cinco novilhos mestiços $F_{1}$ Simental x Nelore, não-castrados, com idade de 18 meses e peso inicial médio de $300 \mathrm{~kg}$, fistulados no rúmen, abomaso e íleo, segundo as técnicas descritas por LEÃO e COELHO da SILVA (1980).

Os animais foram mantidos em regime de confinamento, alojados em baias individuais cobertas de $3 \times 3 \mathrm{~m}$ de área, com piso de concreto revestido de borracha, comedouros de concreto e bebedouros automáticos.

$\mathrm{O}$ delineamento experimental utilizado foi em quadrado latino 5 x 5, com cinco animais, cinco tratamentos e cinco períodos experimentais. 
912 Rev. bras. zootec.

Os tratamentos foram constituídos de fenos dos capins braquiária (Brachiaria decumbens, Stapf) e coast-cross (Cynodon dactylon), em proporções iguais, e mistura concentrada (fubá de milho, farelo de soja, uréia e minerais), nos níveis de 25,0; 37,5; 50,0; 62,5; e 75,0\%. As rações foram balanceadas de acordo com o Cornell Net Carbohydrate and Protein System CNCPS (BARRY et al., 1994). As proporções dos ingredientes nos concentrados estão na Tabela 1; a composição química dos concentrados e fenos, na Tabela 2; e a composição das rações, da Tabela 3.

Os cinco períodos experimentais tiveram duração de 14 dias cada, sendo 10 dias de adaptação à dieta e quatro dias para as coletas de fezes e digestas de abomaso e íleo. Os animais foram pesados no início e no final de cada período experimental.

A ração total foi fornecidaà vontade, emumaúnica vez ao dia, às $8 \mathrm{~h}$, tendo sido as sobras previamente recolhidas e pesadas todos os dias, para determinação do consumo diário. A quantidade de ração fornecida foi calculada de modo a permitir aproximadamente $10 \%$ de sobras, enquanto a água foi fornecida à vontade. Foram realizadas amostras compostas dos fenos fornecidos, dos concentrados, por tratamento, e das sobras, por animal em cada período. Todas estas amostras foram devidamente armazenadas a $-5^{\circ} \mathrm{C}$, posteriormente moídas em moinho com peneira de $1 \mathrm{~mm}$ e submetidas às análises laboratoriais.
Para determinação da excreção fecal e do fluxo de digestas, foi utilizadoo óxido crômico, que foi introduzido por intermédio da fístula ruminal, em duas doses diárias de $10 \mathrm{~g}$ cada, durante os últimos sete dias do período de adaptação e nos quatro dias de coleta de fezes e digestas de abomaso e íleo, sempre às 8 e $17 \mathrm{~h}$.

As coletas de fezes e digestas de abomaso e íleo foram feitas a intervalos de oito horas, com intervalo de seis horas entre dias, de modo que, no final de quatro dias, fossem obtidas 12 amostras de fezes e digestas de abomaso e íleo, por animal, conforme metodologia descrita por CALSAMIGLIA et al. (1995). O esquema foi o seguinte: dia 1 , coletas às 8 , 16 e $24 \mathrm{~h}$; dia 2 , coletas às 6,14 e $22 \mathrm{~h}$; dia 3 , coletas às 4,12 e $20 \mathrm{~h}$; e dia 4 , coletas às 2,10 e $18 \mathrm{~h}$.

As amostras foram armazenadas a $-5^{\circ} \mathrm{C}$ e, posteriormente, pré-secas em estufa ventilada a $65^{\circ} \mathrm{C}$, por 72 a 96 horas, e moídas em moinhos com peneira de malha de $1 \mathrm{~mm}$. Após, foi elaborada uma amostra composta para o período diurno ( 8 às $18 \mathrm{~h}$ ) e noturno (20 às 6 h), por animal, em cada período de coleta, com base no peso seco de cada subamostra. As amostras compostas foram devidamente acondicionadas em recipientes de vidro e posteriormente submetidas às análises laboratoriais.

Os teores de MS, MO, EE e FDN e a dosagem de nitrogênio total $(\mathrm{N})$ foram determinados em todas as

Tabela 1 - Proporção dos ingredientes usados nos concentrados (\%MN)

Table 1 - Ingredients proportion used in the concentration (as fed)

\begin{tabular}{|c|c|c|c|c|c|}
\hline \multirow[t]{2}{*}{$\begin{array}{l}\text { Ingrediente } \\
\text { Ingredient }\end{array}$} & \multicolumn{5}{|c|}{$\begin{array}{l}\text { Concentrado } \\
\text { Concentrate }\end{array}$} \\
\hline & 25,0 & 37,5 & 50,0 & 62,5 & 75,0 \\
\hline Fubá de milho (\%) & 77,77 & 77,41 & 77,34 & 77,25 & 78,75 \\
\hline Corn meal & & & & & \\
\hline $\begin{array}{l}\text { Farelo de soja }(\%) \\
\text { Soybean meal }\end{array}$ & 19,94 & 19,95 & 20,13 & 19,94 & 18,22 \\
\hline $\begin{array}{l}\text { Uréia }(\%) \\
\text { Urea }\end{array}$ & 0,99 & 1,34 & 1,38 & 1,42 & 1,43 \\
\hline $\begin{array}{l}\text { Calcário }(\%) \\
\text { Limestone }\end{array}$ & 0,00 & 0,30 & 0,35 & 0,70 & 0,94 \\
\hline $\begin{array}{l}\text { Fosfato bicálcico }(\%) \\
\text { Dicalcium phosphate }\end{array}$ & 0,26 & 0,26 & 0,26 & 0,26 & 0,26 \\
\hline $\begin{array}{l}\text { Cloreto de sódio (\%) } \\
\text { Sodium chlorate }\end{array}$ & 0,88 & 0,62 & 0,44 & 0,35 & 0,32 \\
\hline $\begin{array}{l}\text { Sulfato de zinco } \\
\text { Zinc sulfate }\end{array}$ & 46,00 & 31,00 & 23,00 & 18,50 & 16,00 \\
\hline $\begin{array}{l}\text { Sulfato de cobre } \\
\text { Copper sulfate }\end{array}$ & 11,50 & 7,40 & 5,60 & 4,40 & 3,50 \\
\hline $\begin{array}{l}\text { Sulfato de cobalto }{ }^{1} \\
\text { Cobalt sulfate }\end{array}$ & 0,20 & 0,12 & 0,10 & 0,10 & 0,10 \\
\hline $\begin{array}{l}\text { Iodato de potássio } \\
\text { Potassium iodate }\end{array}$ & 0,40 & 0,24 & 0,18 & 0,14 & 0,12 \\
\hline
\end{tabular}


TIBO et al.

Tabela 2 - Teor de matéria seca (MS), matéria orgânica (MO), proteína bruta (PB), extrato etéreo (EE), carboidratos totais ( $\mathrm{CHO}$ ), fibra em detergente neutro (FDN) e carboidratos não-estruturais (CNE) dos concentrados e fenos

Table 2 - Content of dry matter (DM), organic matter (OM), crude protein (CP), ether extract (EE), total carbohydrates (CHO), neutral detergent fiber (NDF) and non-structural carbohydrates (NSC) of concentrates and hays

\begin{tabular}{|c|c|c|c|c|c|c|c|}
\hline \multirow[t]{2}{*}{ Item } & \multicolumn{5}{|c|}{$\begin{array}{c}\text { Concentrado } \\
\text { Concentrate }\end{array}$} & \multicolumn{2}{|c|}{$\begin{array}{c}\text { Feno } \\
\text { Hay }\end{array}$} \\
\hline & 25,0 & 37,5 & 50,0 & 62,5 & 75,0 & Braquiária & Coast-cross \\
\hline $\begin{array}{l}\mathrm{MS} \% \\
D M\end{array}$ & 85,56 & 85,25 & 85,09 & 85,57 & 85,53 & 89,48 & 89,56 \\
\hline $\begin{array}{l}\mathrm{MO}^{1} \\
O M\end{array}$ & 96,96 & 96,47 & 96,38 & 96,42 & 96,70 & 94,27 & 93,22 \\
\hline $\begin{array}{l}\mathrm{PB}^{1} \\
C P\end{array}$ & 18,97 & 19,53 & 20,43 & 19,76 & 19,79 & 2,09 & 7,79 \\
\hline $\begin{array}{l}\mathrm{EE}^{1} \\
\mathrm{CHO}^{1}\end{array}$ & $\begin{array}{r}3,36 \\
74,63\end{array}$ & $\begin{array}{r}3,08 \\
73,86\end{array}$ & $\begin{array}{r}3,54 \\
72,41\end{array}$ & $\begin{array}{r}3,33 \\
73,33\end{array}$ & $\begin{array}{r}3,48 \\
73,43\end{array}$ & $\begin{array}{r}0,87 \\
91,31\end{array}$ & $\begin{array}{r}1,03 \\
84,40\end{array}$ \\
\hline $\begin{array}{l}\mathrm{FDN}^{1} \\
N D F\end{array}$ & 11,14 & 12,65 & 11,21 & 13,31 & 12,18 & 81,76 & 82,23 \\
\hline $\begin{array}{l}\mathrm{CNE}^{1} \\
\text { NSC }\end{array}$ & 63,49 & 61,21 & 61,20 & 60,02 & 61,25 & 9,55 & 2,17 \\
\hline
\end{tabular}

${ }^{1}$ Porcentagem na MS (DM percentage).

Tabela 3 - Teor médio de matéria seca (MS), matéria orgânica (MO), proteína bruta (PB), extrato etéreo (EE), carboidratos totais $(\mathrm{CHO})$, fibra em detergente neutro (FDN), carboidratos não-estruturais (CNE), nutrientes digestíveis totais (NDT) e concentração de energia metabolizável (EM), das rações

Table 3 - Average content of dry matter (DM), organic matter $(O M)$, crude protein $(C P)$, ether extract $(E E)$, total carbohydrates (CHO), neutral detergent fiber (NDF), non-structural carbohydrates (NSC), total digestible nutrients (TDN) and metabolizable energy (ME) concentration of the diets

\begin{tabular}{|c|c|c|c|c|c|}
\hline \multirow[b]{2}{*}{ Item } & \multicolumn{5}{|c|}{$\begin{array}{c}\text { Ração experimental } \\
\text { Experimental diet }\end{array}$} \\
\hline & 25,0 & 37,5 & 50,0 & 62,5 & 75,0 \\
\hline MS\% & 88,53 & 87,92 & 87,30 & 87,05 & 86,53 \\
\hline $\begin{array}{l}D M \\
\mathrm{MO}^{1}\end{array}$ & 94,54 & 94,76 & 95,06 & 95,41 & 95,96 \\
\hline $\begin{array}{l}O M \\
\mathrm{~PB}^{1} \\
C P\end{array}$ & 8,45 & 10,41 & 12,68 & 14,20 & 16,08 \\
\hline $\mathrm{EE}^{1}$ & 1,55 & 1,75 & 2,25 & 2,44 & 2,85 \\
\hline $\mathrm{CHO}^{1}$ & 84,55 & 82,60 & 80,13 & 78,77 & 77,03 \\
\hline $\begin{array}{l}\text { FDN }^{1} \\
N D F\end{array}$ & 64,28 & 55,99 & 46,60 & 39,07 & 29,63 \\
\hline $\begin{array}{l}\mathrm{CNE}^{1} \\
N S E\end{array}$ & 20,27 & 26,61 & 33,53 & 39,70 & 47,40 \\
\hline $\begin{array}{l}\text { NDT }^{1} \\
T D N\end{array}$ & 63,04 & 62,51 & 67,31 & 71,33 & 75,26 \\
\hline $\begin{array}{l}\mathrm{EM}^{2} \\
M E\end{array}$ & 2,28 & 2,26 & 2,43 & 2,58 & 2,72 \\
\hline
\end{tabular}

amostras, conforme técnica descrita por SILVA (1990), sendo a PB obtida pela multiplicação do N pelo fator 6,25 .

As análises de cromo nas fezes e nas digestas de abomaso e íleo foram realizadas de acordo com técnica proposta por Williams et al. (1962), citados por SILVA (1990).
Os carboidratos totais (CHO) foram obtidos por intermédio da equação: 100 - (\%PB +\%EE + \% Cinzas), enquanto os carboidratos não-estruturais (CNE), pela diferença entre CHO e FDN (SNIFFEN et al., 1992).

Os teores de nutrientes digestíveis totais (NDT) e energia metabolizável das rações foram calculados conforme recomendações de SNIFFEN et al. (1992). 
914 Rev. bras. zootec.

A comparação das digestibilidades da MS e MO nos períodos diurno e noturno foi feita por meio do delineamento inteiramente casualizado, com dois tratamentos e 25 repetições.

Os dados de consumo e digestibilidade foram avaliados por meio de análises de variância e regressão, utilizando-se o programa SAEG - Sistema de Análises Estatísticas e Genéticas (UFV, 1995).

Os modelos foram escolhidos com base na significância dos coeficientes de regressão, utilizando-se o teste " $t$ " em nível de $5 \%$ de probabilidade, e nos coeficientes de determinação.

\section{Resultados e Discussão}

Os consumos médios diários de MS, MO, PB, EE, CHO, FDN, CNE e NDT, expressos em quilogramas por dia (kg/dia), e os consumos de MS, FDN e NDT, expressos em porcentagem do peso vivo (\%PV) e em gramas por unidade de tamanho metabólico $\left(\mathrm{g} / \mathrm{kg}^{0,75}\right)$, com respectivas equações de regressão e coeficientes de variação e determinação, são demonstrados na Tabela 4.

Os consumos de MS pelos animais, expressos em $\mathrm{kg} / \mathrm{dia}, \% \mathrm{PV}$ e $\mathrm{g} / \mathrm{kg}^{0,75}$, aumentaram linearmente

Tabela 4 - Médias e regressão dos consumos de matéria seca (MS), matéria orgânica (MO), proteína bruta (PB), extrato etéreo (EE), carboidratos totais $(\mathrm{CHO})$, fibra em detergente neutro (FDN), carboidratos nãoestruturais (CNE) e nutrientes digestíveis totais (NDT) em relação aos níveis de concentrado nas rações

Table 4 - Means and regression of the intake of dry matter (DM), organic matter (OM), crude protein (CP), ether extract (EE), total carbohydrates (CHO), neutral detergent fiber (NDF), non-structural carbohydrates (NSC) and total digestible nutrients (TDN) on the concentrate levels in the diets

\begin{tabular}{|c|c|c|c|c|c|c|c|c|}
\hline \multirow[t]{2}{*}{ Item } & \multicolumn{5}{|c|}{$\begin{array}{c}\text { Nível de concentrado } \\
\text { Concentrate level }\end{array}$} & \multirow[t]{2}{*}{$\begin{array}{l}\text { Regressão } \\
\text { Regression }\end{array}$} & \multirow[t]{2}{*}{$\mathrm{r}^{2}$} & \multirow[t]{2}{*}{ CV\% } \\
\hline & 25,0 & 37,5 & 50,0 & 62,5 & 75,0 & & & \\
\hline \multicolumn{9}{|c|}{$\mathrm{kg} / \mathrm{dia}(\mathrm{kg} /$ day $)$} \\
\hline $\begin{array}{l}7 \mathrm{MS} \\
D M\end{array}$ & 5,11 & 5,94 & 6,13 & 6,68 & 6,63 & $\hat{Y}=4,583+0,030 * * X$ & 0,88 & 8,03 \\
\hline $\begin{array}{l}\mathrm{MO} \\
\mathrm{OM}\end{array}$ & 4,85 & 5,65 & 5,84 & 6,38 & 6,37 & $\hat{\mathrm{Y}}=4,304+0,030 * * \mathrm{X}$ & 0,90 & 8,09 \\
\hline $\begin{array}{l}\mathrm{PB} \\
C P\end{array}$ & 0,46 & 0,64 & 0,84 & 0,96 & 1,07 & $\hat{Y}=0,183+0,012 * * X$ & 0,98 & 9,38 \\
\hline $\begin{array}{l}\mathrm{EE} \\
\mathrm{CHO} \\
\mathrm{FDN} \\
N D F\end{array}$ & $\begin{array}{l}0,09 \\
4,29 \\
3,14\end{array}$ & $\begin{array}{l}0,11 \\
4,89 \\
3,25\end{array}$ & $\begin{array}{l}0,15 \\
4,85 \\
2,55\end{array}$ & $\begin{array}{l}0,17 \\
5,24 \\
2,52\end{array}$ & $\begin{array}{l}0,21 \\
5,09 \\
1,89\end{array}$ & $\begin{array}{l}\hat{Y}=0,027+0,002 * * X \\
\hat{Y}=4,095+0,016 * * X \\
\hat{Y}=3,965-0,026 * * X\end{array}$ & $\begin{array}{l}0,98 \\
0,73 \\
0,87\end{array}$ & $\begin{array}{l}8,66 \\
8,15 \\
9,78\end{array}$ \\
\hline $\begin{array}{l}\mathrm{CNE} \\
N S C\end{array}$ & 1,15 & 1,65 & 2,30 & 2,72 & 3,21 & $\hat{Y}=0,130+0,041 * * X$ & 0,99 & 9,90 \\
\hline $\begin{array}{l}\text { NDT } \\
T D N \\
\end{array}$ & 3,19 & 3,71 & 4,12 & 4,76 & 4,99 & $\hat{Y}=2,294+0,037 * * X$ & 0,99 & 9,09 \\
\hline \multicolumn{9}{|c|}{$\% \mathrm{PV}(\% L W)$} \\
\hline $\begin{array}{l}\text { MS } \\
D M\end{array}$ & 1,55 & 1,81 & 1,87 & 2,03 & 2,00 & $\hat{\mathrm{Y}}=1,402+0,009 * * \mathrm{X}$ & 0,85 & 8,15 \\
\hline $\begin{array}{l}\text { FDN } \\
N D F\end{array}$ & 0,95 & 0,99 & 0,78 & 0,77 & 0,56 & $\hat{Y}=1,209-0,008 * * X$ & 0,86 & 10,30 \\
\hline $\begin{array}{l}\text { NDT } \\
T D N \\
\end{array}$ & 0,97 & 1,13 & 1,26 & 1,45 & 1,50 & $\hat{Y}=0,707+0,011 * * X$ & 0,98 & 8,47 \\
\hline \multicolumn{9}{|c|}{$\mathrm{g} / \mathrm{kg}^{0,75}$} \\
\hline $\begin{array}{l}\text { MS } \\
D M\end{array}$ & 65,96 & 77,00 & 79,49 & 86,43 & 85,11 & $\hat{Y}=59,706+0,382 * * X$ & 0,85 & 8,11 \\
\hline $\begin{array}{l}\text { FDN } \\
N D F\end{array}$ & 40,59 & 42,05 & 33,04 & 32,64 & 24,10 & $\hat{Y}=51,433-0,339 * * X$ & 0,86 & 10,18 \\
\hline $\begin{array}{l}\text { NDT } \\
T D N\end{array}$ & 41,30 & 47,97 & 53,42 & 61,61 & 64,06 & $\hat{Y}=30,002+0,473 * * X$ & 0,98 & 8,57 \\
\hline
\end{tabular}


$(\mathrm{P}<0,01)$ com o incremento nos níveis de concentrado da ração, comportamento inverso ao verificado para o consumo de FDN. O consumo de MS foi possivelmente controlado pela demanda de energia, porque os níveis de consumo de FDN foram inferiores ao valor de 1,2\% PV sugerido por MERTENS (1992).

LADEIRA (1998) e DIAS (1999), trabalhando com proporções similares de volumosos e concentrados às do presente trabalho, na dieta de zebuínos e mestiços, respectivamente, verificaram comportamento de consumo semelhante. Contrariamente, STOKES et al. (1991) e CARVALHO et al. (1997a) não constataram efeito do nível de concentrados na dieta sobre a ingestão de MS.

FERREIRA (1997) também observou aumento linear no consumo de MS com o incremento nos níveis de concentrado da dieta. Vale ressaltar que esse autor trabalhou em condições de confinamento, utilizando o mesmo tipo de dieta e animais semelhantes aos do presente trabalho.

Os consumos de $\mathrm{MO}$ e $\mathrm{CHO}$ cresceram linearmente $(\mathrm{P}<0,01)$ com o aumento nas proporções de concentrado nas rações, refletindo o mesmo comportamento verificado para a MS.

Tabela 5 - Médias e coeficientes de variação (CV\%) das digestibilidades aparente de matéria seca e orgânica (DAMS e DAMO), no rúmen (DRMS e DRMO), no intestino delgado (DIDMS e DIDMO), no intestino grosso (DIGMS e DIGMO) e no intestino total (DITMS e DITMO), nos períodos do dia e da noite

Table 5 - Mean and coefficient of variation for the total apparent digestibility of dry matter and organic matter (ADDM and $A D O M$ ), in the rumen (RDDM and RDOM), in the small intestine (SIDDM and SIDOM), in the large intestine (LIDDM and LIDOM), and in the total intestine (TIDMS AND TIDOM) in the periods of day or night

\begin{tabular}{lccr}
\hline \multicolumn{3}{c}{ Metodologia } & \\
\cline { 2 - 3 } Item & \multicolumn{2}{c}{ Methodology } & \\
\cline { 2 - 3 } & Dia & Noite & CV\% \\
& Day & Night & \\
\hline DAMS (ADDM) & $67,91^{\mathrm{a}}$ & $65,76^{\mathrm{a}}$ & 8,30 \\
DAMO (ADDO) & $69,73^{\mathrm{a}}$ & $67,89^{\mathrm{a}}$ & 7,58 \\
DRMS (RDDM) & $62,71^{\mathrm{a}}$ & $64,46^{\mathrm{a}}$ & 13,85 \\
DRMO (RDOM) & $68,41^{\mathrm{a}}$ & $66,59^{\mathrm{a}}$ & 12,35 \\
DIDMS (SIDDM) & $25,17^{\mathrm{a}}$ & $29,15^{\mathrm{a}}$ & 44,23 \\
DIDMO (SIDOM) & $25,71^{\mathrm{a}}$ & $29,76^{\mathrm{a}}$ & 40,22 \\
DIGMS (LIDDM) & $9,49^{\mathrm{a}}$ & $7,63^{\mathrm{a}}$ & 89,03 \\
DIGMO (LIDDM) & $6,48^{\mathrm{a}}$ & $6,04^{\mathrm{a}}$ & 108,19 \\
DITMS (TIDDM) & $36,48^{\mathrm{a}}$ & $35,54^{\mathrm{a}}$ & 24,28 \\
DITMO (TIDOM) & $31,57^{\mathrm{a}}$ & $33,41^{\mathrm{a}}$ & 25,67 \\
\hline
\end{tabular}

Médias, na linha, seguidas por letras diferentes são diferentes pelo teste $F(P<0,05)$.

Means, within a row, followed by different letters are different by $F$ test $(P<.05)$.
Os aumentos lineares $(\mathrm{P}<0,01)$ de consumo verificados para $\mathrm{PB}, \mathrm{EE}$ e CNE podem ser atribuídos ao aumento no consumo de MS e à maior concentração destes nutrientes nas rações com maiores teores de concentrado. Este fato também se refletiu sobre o consumo de NDT, que aumentou linearmente $(\mathrm{P}<0,01)$ com o nível de concentrado, em virtude possivelmente da maior ingestão de CNE e outros nutrientes mais digestíveis, em detrimento do consumo de FDN.

Os dados referentes à comparação entre as digestibilidades aparentes totais e parciais da MS e MO, nos períodos de dia (8-18h) e noite (20-6h), são encontrados na Tabela 5. Pode-se observar que não houve diferença significativa $(\mathrm{P}>0,05)$ nas digestibilidades aparentes calculadas das amostras obtidas nos períodos diurno e noturno. De acordo com estes resultados, pode-se inferir que a realização de coletas somente durante o dia seria suficiente para se obterem amostras representativas das fezes e das digestas de abomaso e íleo. Os resultados deste trabalho também foram semelhantes aos encontrados por LADEIRA (1998), que trabalhou com os mesmos níveis de concentrado e volumosos fornecidos a novilhos Nelore.

Portanto, as amostras que foram separadas por dia e noite foram misturadas, resultando, assim, em amostras compostas por animal e tratamento, para as demais análises.

Os coeficientes de digestibilidades aparentes totais e parciais da MS e MO, assim como as equações de regressão e os coeficientes de variação e determinação, são apresentados na Tabela 6 .

As digestibilidades aparentes totais da MS e MO aumentaram linearmente $(\mathrm{P}<0,01)$ com o aumento dos níveis de concentrado na ração, provavelmente refletindo o aumento dos consumos de carboidratos nãoestruturais. Aumento linear para as digestibilidades aparentes totais da MS e da MO também foi descrito por GONÇALVES et al. (1991), BERCHIELLI (1994), ARAÚJO et al. (1998), SIGNORETTI et al. (1998) e DIAS (1999). Por outro lado, LADEIRA (1998) constatou comportamento quadrático, com ponto de mínimo, para as digestibilidades da MS e MO.

A digestibilidade aparente da MS no rúmen não diferiu entre tratamentos $(\mathrm{P}>0,05)$, apresentando média de $63,04 \%$, valor próximo aos $63,35 \%$ relatados por LADEIRA (1998), mas superior aos 48,52 e $57,48 \%$ observados, respectivamente, por BÜRGER et al. (1998) e DIAS (1999). A digestibilidade aparente ruminal da MO apresentou comportamento quadrático $(\mathrm{P}<0,05)$, com ponto de mínimo de $64,83 \%$ 
916 Rev. bras. zootec.

Tabela 6 - Médias e regressão das digestibilidades aparentes total, ruminal e intestinal total, de matéria seca (MS) e matéria orgânica (MO) em relação aos níveis de concentrado nas rações

Table 6 - Means and regression of the total, ruminal and intestinal apparent digestibilities of dry matter (DM) and organic matter (OM) on the concentrate levels in the diets

\begin{tabular}{|c|c|c|c|c|c|c|c|c|}
\hline \multirow[t]{2}{*}{ Item } & \multicolumn{5}{|c|}{$\begin{array}{l}\text { Nível de concentrado } \\
\text { Concentrate level }\end{array}$} & \multirow[t]{2}{*}{$\begin{array}{l}\text { Regressão } \\
\text { Regression }\end{array}$} & \multirow[t]{2}{*}{$\mathrm{r}^{2}$} & \multirow[t]{2}{*}{$\mathrm{CV} \%$} \\
\hline & 25,0 & 37,5 & 50,0 & 62,5 & 75,0 & & & \\
\hline \multicolumn{9}{|c|}{$\begin{array}{l}\text { Digestibilidade total } \\
\text { Total digestibility }\end{array}$} \\
\hline MS & 62,65 & 62,01 & 66,12 & 70,17 & 73,22 & $\hat{Y}=55,110+0,234 * * X$ & 0,92 & 4,43 \\
\hline$D M$ & & & & & & & & \\
\hline MO & 65,22 & 64,17 & 68,02 & 71,84 & 74,79 & $\hat{Y}=58,083+0,214 * * X$ & 0,90 & 4,08 \\
\hline$O M$ & & & & & & & & \\
\hline \multirow{2}{*}{\multicolumn{9}{|c|}{$\begin{array}{l}\text { Digestibilidade ruminal } \\
\text { Ruminal digestibility }^{1}\end{array}$}} \\
\hline & & & & & & & & \\
\hline MS & 62,25 & 67,30 & 59,45 & 64,19 & 62,02 & $\hat{Y}=63,04$ & & 11,86 \\
\hline$D M$ & & & & & & & & \\
\hline MO & 73,95 & 67,91 & 62,82 & 66,25 & 65,60 & $\hat{Y}=95,354-1,105 * X+$ & 0,90 & 8,04 \\
\hline$O M$ & & & & & & $0,010 * X^{2}$ & & \\
\hline \multicolumn{9}{|c|}{ Digestibilidade intestinal total $^{1}$} \\
\hline & \multicolumn{5}{|c|}{ Total ruminal digestibility } & & & \\
\hline MS & 37,75 & 32,70 & 40,55 & 35,81 & 37,98 & $\hat{Y}=36,96$ & & 20,24 \\
\hline$D M$ & & & & & & & & \\
\hline MO & 26,05 & 32,09 & 37,18 & 33,75 & 34,40 & $\hat{Y}=25,212+0,150 * X$ & 0,51 & 17,65 \\
\hline$O M$ & & & & & & & & \\
\hline
\end{tabular}

* $e^{* *}$ Significativo a 5 e $1 \%$, respectivamente, pelo teste $t$.

$\mathrm{X}=$ nível de concentrado da dieta.

1 Digestibilidade calculada em função do total digestível.

* and ${ }^{*}$ Significant at 5 and $1 \%$, respectively, by $t$ test.

$X=$ concentrate level in the diet.

1 Digestibility calculated in function of total digestible.

para o nível de $55,3 \%$ de concentrado na dieta.

Em virtude de ter ocorrido perda de duas fístulas ileais, foram obtidos os valores médios e respectivos desvios-padrão para os coeficientes de digestibilidade aparente da MS no intestino delgado e no intestino grosso de $28,70 \pm 8,09$ e $8,61 \pm 5,96 \%$. Os coeficientes de digestibilidade aparente médios da MO foram de $27,74 \pm 9,13$ e $5,96 \pm 5,67$, respectivamente, para os mesmos sítios de digestão.

A digestão da MS no intestino total foi, em média, $36,96 \%$ e não foi influenciada pelos níveis de concentrado ( $\mathrm{P}>0,05)$, enquanto o aumento linear $(\mathrm{P}<0,05)$ na digestão intestinal da $\mathrm{MO}$ pode ser explicado pelo maior escape ruminal de MO nas rações mais ricas em concentrado.

LADEIRA (1998) observou comportamento linear crescente e decrescente para as digestibilidades aparentes no intestino delgado e grosso, respectivamente. CARVALHO et al. (1997b), entretanto, relataram valores médios de digestibilidades aparentes, respectivamente, para MS e MO, de 31,95 e 27,08\%, no intestino delgado, e 5,50 1,38\%, no intestino grosso.

As digestibilidades aparentes totais de PB e EE apresentaram incrementos lineares com o aumento na proporção de concentrado da dieta (Tabela 7), o que pode ser explicado pela redução relativa da contribuição das perdas endógenas e pelo aumento no consumo destes nutrientes.

Os valores de digestibilidade aparente total da PB observados são semelhantes aos obtidos por LADEIRA (1998), que também encontrou efeito linear do nível de concentrado sobre a digestão da PB. CARVALHO et al. (1997a) não observaram efeito do nível de concentrado sobre a digestibilidade aparente da PB e do EE, obtendo coeficientes médios de digestibilidade aparente da ordem de 63,50 e 79,90\% para $\mathrm{PB}$ e EE, respectivamente.

Os coeficientes de digestibilidade aparente no rúmen para a $\mathrm{PB}$ apresentaram valores negativos para 25,0 e $37,5 \%$ de concentrado nas dietas, demonstrando que não houve perda de nitrogênio na forma de amônia, o que, segundo LADEIRA (1998), pode ser indicativo de deficiência dietética de proteína, em que os teores de proteína foram menores, uma vez que as rações não eram isoprotéicas. Foi observado 
efeito linear crescente $(\mathrm{P}<0,01)$ do nível de concentrado sobre a digestibilidade ruminal da $\mathrm{PB}$. Os valores positivos de 15,19 e 22,85\%, obtidos para as rações com 62,5 e $75 \%$ de concentrados, possivelmente, indicam que os teores de PB usados nestas rações (14,20 e 16,08\%, Tabela 3) foram acima das exigências.

Valores negativos para os coeficientes de digestibilidade aparente do EE no rúmen foram observados para todos os tratamentos, indicando que pode ter havido síntese de lipídios microbianos (CARVALHO et al.,1997b; VALADARES et al., 1997; e DIAS, 1999).

Os valores médios para as digestibilidades aparentes da $\mathrm{PB}$, do $\mathrm{EE}$ e dos compostos nitrogenados não-amoniacais (NNA), no intestino delgado, e os respectivos desvios-padrão foram, respectivamente, $64,70 \pm 4,46 ; 79,21 \pm 3,69$ e $66,24 \pm 4,07 \%$. No intestino grosso, as digestibilidades aparente médias de PB e EE foram de $-2,48 \pm 14,20$ e $-13,73 \pm 5,24 \%$.

A digestibilidade intestinal total da PB foi, em média, 65,30\%, não sendo influenciada pelos níveis de concentrado das dietas $(\mathrm{P}>0,05)$. Segundo o NRC (1985), a digestibilidade aparente do NNAé de 65,00\%, valor bastante semelhante ao encontrado neste trabalho para a digestibilidade intestinal da PB. A digestibilidade intestinal total do teor de EE aumentou linear- mente $(\mathrm{P}<0,01)$ com os níveis de concentrado da dieta. Os valores encontrados foram inferiores ao citado pelo CNCPS, descrito por SNIFFEN et al. (1992), de $95 \%$.

Os coeficientes de digestibilidade aparente e os locais de digestão de CHO, FDN e CNE, mostrados na Tabela 8 , indicam que as digestibilidades aparentes totais de CHO $(\mathrm{P}<0,01)$ e $\mathrm{CNE}(\mathrm{P}<0,05)$ elevaram-se com o aumento dos níveis de concentrados nas rações, enquanto a digestibilidade da FDN demonstrou comportamento linear decrescente $(\mathrm{P}<0,05)$. $\mathrm{O}$ aumento na digestibilidade aparente total para CHO pode ser atribuído, principalmente, à maior proporção de CNE nas dietas com níveis mais altos de concentrados.

O comportamento verificado para a digestão total da FDN pode ser explicado pelo fato de que aumentos nas proporções de concentrado nas dietas tendem a provocar redução da digestibilidade aparente total da FDN, em razão da depressão da digestibilidade ruminal da fibra.

A digestibilidade ruminal dos $\mathrm{CHO}$ decresceu $(\mathrm{P}<0,01)$ com o aumento dos níveis de concentrados na dieta, devido, possivelmente, à redução da digestibilidade da FDN, apesar desta não ter apre-

Tabela 7 - Médias e regressão das digestibilidades aparente total, ruminal e intestinal total da proteína bruta (PB) e do extrato etéreo (EE), em relação aos níveis de concentrado nas rações

Table 7 - Means and regression of the total, ruminal and intestinal apparent digestibilities of crude protein (CP) and ether extract (EE) on the concentrate levels in the diets

\begin{tabular}{|c|c|c|c|c|c|c|c|c|}
\hline \multirow[t]{2}{*}{ Item } & \multicolumn{5}{|c|}{$\begin{array}{l}\text { Nível de concentrado } \\
\text { Concentrate level }\end{array}$} & \multirow[t]{2}{*}{$\begin{array}{l}\text { Regressão } \\
\text { Regression }\end{array}$} & \multirow[t]{2}{*}{$\mathrm{r}^{2}$} & \multirow[t]{2}{*}{ CV\% } \\
\hline & 25,0 & 37,5 & 50,0 & 62,5 & 75,0 & & & \\
\hline \multicolumn{9}{|c|}{$\begin{array}{l}\text { Digestibilidade total } \\
\text { Total digestibility }\end{array}$} \\
\hline $\begin{array}{l}\mathrm{PB} \\
C P\end{array}$ & 59,97 & 61,48 & 69,81 & 71,84 & 74,98 & $\hat{Y}=51,460+0,323 * * X$ & 0,94 & 3,60 \\
\hline $\mathrm{EE}$ & 61,32 & 64,29 & 76,78 & 80,50 & 81,89 & $\hat{Y}=50,015+0,459 * * X$ & 0,91 & 5,55 \\
\hline \multicolumn{9}{|c|}{$\begin{array}{l}\text { Digestibilidade ruminal }^{1} \\
\text { Ruminal digestibility }^{2}\end{array}$} \\
\hline $\begin{array}{l}\mathrm{PB} \\
C P\end{array}$ & $-11,51$ & $-2,11$ & 8,35 & 15,19 & 22,85 & $\hat{Y}=-27,855+0,688 * * X$ & 0,99 & 146,14 \\
\hline $\mathrm{EE}$ & $-28,05$ & $-35,40$ & $-14,99$ & $-8,93$ & $-2,01$ & $\hat{Y}=-49,301+0,628 * * X$ & 0,82 & 101,37 \\
\hline \multicolumn{9}{|c|}{$\begin{array}{c}\text { Digestibilidade intestinal total } \\
\text { Total ruminal digestibility }\end{array}$} \\
\hline $\begin{array}{l}\mathrm{PB} \\
C P\end{array}$ & 63,72 & 62,08 & 66,96 & 66,40 & 67,38 & $\hat{Y}=65,30$ & & 6,68 \\
\hline $\mathrm{EE}$ & 69,70 & 72,87 & 79,72 & 82,02 & 82,31 & $\hat{Y}=63,570+0,275^{* *} X$ & 0,90 & 4,99 \\
\hline
\end{tabular}

* $e^{* *}$ Significativo a 5 e $1 \%$, respectivamente, pelo teste $t$.

$\mathrm{X}=$ nível de concentrado da dieta.

1 Expressa em função da quantidade que chegou a cada local.

* and ** Significant at 5 and $1 \%$, respectively, by $t$ test.

$X$ - concentrate level in the diet.

1 Express in function of the amount that arrived in each place. 
918 Rev. bras. zootec.

sentado diferença significativa.

As digestibilidades aparente médias e os respectivos desvios-padrão no intestino delgado obtidas para CHO, FDN e CNE foram 10,13 $\pm 9,35 ;-5,67 \pm 23,62$ e $25,38 \pm 4,43 \%$, respectivamente. As digestões aparentes médias encontradas para CHO e CNE no intestino

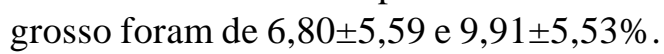

A digestibilidade intestinal total dos $\mathrm{CHO}$ aumentou linearmente $(\mathrm{P}<0,01)$ com os níveis de concentrado na dieta, ocorrendo o inverso para os CNE; para a $\mathrm{FDN}$, não houve efeito significativo $(\mathrm{P}>0,05)$, apresentando valor médio de $-4,42 \%$.

A partir das concentrações de FDN e dos respectivos valores de NDT e de digestibilidade total da MS (DIGTMS) das rações, observados neste trabalho, foram estabelecidas algumas relações e obtiveram-se as seguintes equações lineares: $\mathrm{NDT}=86,0834-0,3862 \mathrm{FDN}\left(\mathrm{r}^{2}=0,93 ; \mathrm{P}<0,01\right)$ e DIGTMS $=82,5353-0,3333$ FDN $\left(\mathrm{r}^{2}=0,87\right.$; $\mathrm{P}<0,05)$. Pode-se observar, por meio destas equações, que as concentrações de FDN das dietas são inversamente correlacionadas com os níveis de energia expressos em NDT e com a DIGTMS. Em razão dos elevados coeficientes de determinação $\left(\mathrm{r}^{2}\right)$ obtidos, estas equações podem estimar com alguma segurança o valor energético das rações, a partir do seu teor de FDN, que se constitui em análise simples e de custo reduzido. Assim, em rações contendo 50\% de FDN, os valores estimados para o NDT e a DIGTMS seriam de 66,77 e $65,87 \%$, respectivamente. Estes resultados são, aproximadamente, $5 \%$ inferiores aos valores de 70,16 e 70,20\%, estimados por LADEIRA (1998), e $15 \%$ superiores aos obtidos por DIAS (1999), de 54,23 e $56,17 \%$ de NDT e DIGTMS, respectivamente, para o mesmo nível de FDN na ração.

Tabela 8 - Médias e regressão das digestibilidades aparente total, ruminal e intestinal total de carboidratos totais $(\mathrm{CHO})$, fibra em detergente neutro (FDN) e carboidratos não-estruturais (CNE) em relação aos níveis de concentrado nas rações

Table 8 - Means and regression of the total, ruminal and intestinal apparent digestibilities of the total carbohydrates (CHO), neutral detergent fiber (NDF) and non structural carbohydrates (NSC) on the concentrate levels in the diets

\begin{tabular}{|c|c|c|c|c|c|c|c|c|}
\hline \multirow[t]{2}{*}{ Item } & \multicolumn{5}{|c|}{$\begin{array}{c}\text { Nível de concentrado } \\
\text { Concentratelevel }\end{array}$} & \multirow[t]{2}{*}{$\begin{array}{l}\text { Regressão } \\
\text { Regression }\end{array}$} & \multirow[t]{2}{*}{$\mathrm{r}^{2}$} & \multirow[t]{2}{*}{$\mathrm{CV} \%$} \\
\hline & 25,0 & 37,5 & 50,0 & 62,5 & 75,0 & & & \\
\hline & \multicolumn{7}{|c|}{ Digestibilidade total } & \\
\hline $\mathrm{CHO}$ & 65,56 & 64,54 & 67,46 & 71,62 & 74,60 & $\hat{Y}=58,697+0,201 * * X$ & 0,88 & 4,65 \\
\hline $\begin{array}{l}\text { FDN } \\
N D F\end{array}$ & 57,76 & 52,40 & 46,55 & 51,19 & 46,66 & $\hat{Y}=60,284-0,187 * X$ & 0,64 & 11,17 \\
\hline $\mathrm{CNE}$ & 86,84 & 88,38 & 90,40 & 90,46 & 90,60 & $\hat{Y}=85,549+0,076^{*} X$ & 0,80 & 2,66 \\
\hline \multicolumn{9}{|c|}{$\begin{array}{l}\text { Digestibilidade ruminal } \\
\text { Ruminal digestibility }^{1}\end{array}$} \\
\hline $\mathrm{CHO}$ & 88,23 & 87,07 & 80,81 & 82,04 & 78,56 & $\hat{Y}=93,096-0,195^{* *} X$ & 0,86 & 6,58 \\
\hline FDN & 105,80 & 112,89 & 104,26 & 100,18 & 98,98 & $\hat{Y}=104,42$ & & 9,74 \\
\hline$N D F$ & & & & & & & & \\
\hline $\mathrm{CNE}$ & 56,92 & 57,88 & 68,19 & 72,72 & 72,27 & $\hat{Y}=47,380+0,364 * X$ & 0,88 & 9,26 \\
\hline$\underline{N S C}$ & & & & & & & & \\
\hline \multicolumn{9}{|c|}{$\begin{array}{c}\text { Digestibilidade intestinal total }{ }^{1} \\
\text { Total ruminal digestibility }\end{array}$} \\
\hline $\mathrm{CHO}$ & 11,77 & 12,92 & 19,19 & 17,96 & 21,44 & $\hat{Y}=6,904+0,195 * * X$ & 0,86 & 32,91 \\
\hline FDN & $-5,80$ & $-12,89$ & $-4,26$ & $-0,18$ & 1,01 & $\hat{Y}=-4,42$ & & 230,21 \\
\hline$N D F$ & & & & & & & & \\
\hline $\mathrm{CNE}$ & 43,08 & 42,12 & 31,81 & 27,28 & 27,73 & $\hat{Y}=52,619-0,364 * * X$ & 0,88 & 17,66 \\
\hline$N S C$ & & & & & & & & \\
\hline \multicolumn{9}{|c|}{$\begin{array}{l}{ }^{*} \mathrm{e}^{* *} \text { Significativo a } 5 \text { e } 1 \% \text { de probabilidade, respectiva } \\
\mathrm{X}=\text { nível de concentrado da dieta. } \\
1 \text { Digestibilidade calculada em função do total digestível. } \\
{ }^{*} \text { and }{ }^{* *} \text { Significant at } 5 \text { and } 1 \% \text {, respectively, by } t \text { test. } \\
X=\text { concentrate level in the diet. }\end{array}$} \\
\hline
\end{tabular}




\section{Conclusões}

O consumo de MS, MO e NDT aumentou e o de FDN decresceu linearmente com o aumento nas proporções de concentrado nas dietas.

As digestibilidades aparentes totais e parciais da MS e MO, obtidas de coletas realizadas das 8 às $18 \mathrm{~h}$ e das 20 às $6 \mathrm{~h}$, não diferiram.

As coletas de fezes e de digestas de abomaso e íleo obtidas no período diurno resultaram em amostras representativas.

As digestibilidades aparentes totais de MS, MO, $\mathrm{PB}, \mathrm{EE}, \mathrm{CHO}$ e CNE cresceram linearmente com o aumento nos níveis de concentrados nas rações.

As digestibilidades aparentes da MS, no rúmen e pós-rúmen, foram, em média, de 63,04 e 36,96\%, respectivamente.

A redução dos níveis de FDN das rações resultou em aumentos lineares para o NDT e para a digestibilidade aparente total da MS.

\section{Referências Bibliográficas}

ARAÚJO, G.G.L., COELHO DA SILVA, J.F., VALADARES FILHO, S.C. et al. 1998. Consumo e digestibilidade total dos nutrientes de dietas contendo diferentes níveis de volumoso, em bezerros. R. Bras. Zootec., 27(2):345-354.

BARRY, M.C., FOX, D.C., TYLUTKY, T.P. et al. 1994. A manual for using Cornell net carbohidrate and protein system for evaluating cattle diets. Ithaca; Cornell University. 40p.

BERCHIELLI, T.T. Efeito da relação volumoso:concentrado sobre a partição da digestão, a síntese de proteína microbiana, produção de ácidos graxos voláteis e o desempenho de novilhos em confinamento. Belo Horizonte MG: UFMG, 1994. 104p. Tese (Doutorado em Zootecnia) - Universidade Federal de Minas Gerais, 1994.

BÜRGER, P.J., PEREIRA, J.C., COELHO da SILVA, J.F. et al. Consumo e digestibilidade em bezerros alimentados com dietas contendo níveis de concentrado. In: REUNIÃO ANUAL DA SOCIEDADE BRASILEIRA DE ZOOTECNIA, 35, 1998, Botucatu, SP. Anais... Botucatu: SBZ, 1998, p. 599-601.

CAlSAMIGLIA, S., CAJA, G., STERN, M.D. et al. 1995. Effects of ruminal versus duodenal dosing of fish meal on ruminal fermentation and milk composition. J. Dairy Sci., 78(9):1999-2007.

CARVALHO, A.U., VALADARES FILHO, S.C., COELHO DA SILVA, J.F. et al. 1997a. Níveis de concentrados em dietas de zebuínos. 1. Consumo e digestibilidade aparente. Rev. Bras. Zootec., 26(5):986-995.

CARVALHO, A.U., VALADARES FILHO, S.C., COELHO DA SILVA, J.F. et al. 1997b. Níveis de concentrados em dietas de zebuínos. 2. Coeficientes de digestibilidades aparentes parciais. Rev. Bras. Zootec., 26(5):996-1006.

CECAVA, M.J., MERCHEN, R., BERGER, L.L. et al. 1988. Effects of dietary energy level and protein source on site of digestion and duodenal nitrogen and amino acid flows in steers. J. Anim. Sci., 66:961-974.

DIAS, H.L.C. Consumo, digestibilidade e eficiência microbiana em novilhos $F 1$ Limousin X Nelore alimentados com dietas contendo cinco níveis de concentrado. Viçosa MG: UFV, 1998, 76p. Dissertação (Mestrado em Zootecnia) - Universidade Federal de Viçosa, 1999.

FERREIRA, M.A. Desempenho, exigências nutricionais e eficiência de utilização da energia metabolizável para ganho de peso de bovinos F1 Simental x Nelore. Viçosa MG: UFV, 1997. 97p. Tese (Doutorado em Zootecnia) - Universidade Federal de Viçosa, 1997.

GONÇALVES, L.C. Digestibilidade, composição corporal, exigências nutricionais e características das carcaças de zebuínos, taurinos e bubalinos. Viçosa, MG:UFV, 1988. 238 p. Tese (Doutorado em Zootecnia) - Universidade Federal de Viçosa, 1988.

GONÇALVES, L.C., COELHO DA SILVA, J.F., ESTEVÃO, M.M. et al. 1991. Consumo e digestibilidade da matéria seca e da energia em zebuínos e taurinos, seus mestiços e bubalinos. R. Bras. Zootec., 20(4):384-404.

HOOVER, W.H. 1986. Chemical factores involved in ruminal fiber digestion. J. Dairy Sci., 69(6):2755-2766.

HOOVER, W.H. 1978. Digestion and absorption in the hindgut of ruminants. J. Anim. Sci. 46(4):1789-1799.

LADEIRA, M.M. Consumo e digestibilidades aparentes totais e parciais de dietas contendo diferentes níveis de concentrado, em novilhos Nelore. Viçosa, MG: UFV, 1998. 71p. Dissertação (Mestrado em Zootecnia) - Universidade Federal de Viçosa, 1998.

LEÃO, M.I., COELHO DA SILVA, J.F. Técnicas de fistulação de abomaso em bezerros. In: REUNIÃO ANUAL DA SOCIEDADE BRASILEIRA DE ZOOTECNIA, 17, 1980, Fortaleza, Anais... Fortaleza: SBZ, 1980. p.37.

MERTENS, D. R. Análise da fibra e sua utilização na avaliação e formulação de rações. In: SIMPÓSIO INTERNACIONAL DE RUMINANTES, REUNIÃO ANUAL DA SOCIEDADE BRASILEIRA DE ZOOTECNIA, 29, 1992, Lavras. Anais... Lavras: SBZ, 1992. p.188-219.

NATIONAL RESEARCH COUNCIL - NRC. 1996. Nutrient requirements of beef cattle. 7.ed. Washington National Academy. 242p.

NATIONAL RESEARCH COUNCIL - NRC. 1985. Ruminant nitrogen usage. Washington D.C. $138 \mathrm{p}$.

NOLLER, C.H., NASCIMENTO JR., D., QUEIROZ, D.S. Determinando as exigências nutricionais de animais em pastejo. In: SIMPÓSIO SOBRE MANEJO DE PASTAGENS, 13, 1996, Piracicaba. Anais... Piracicaba, SP:FEALQ, 1996.

SIGNORETTI, R.D. Consumo, digestibilidade, composição corporal, exigências nutricionais e eficiência de utilização da energia metabolizável para ganho de peso de bezerros holandeses. Viçosa, MG: UFV, 1998. 157 p. Tese (Doutorado em Zootecnia) - Universidade Federal de Viçosa, 1998.

SIGNORETTI, R.D., COELHO DA SILVA, J.F., VALADARES FILHO, S.C. et al. Consumo e digestibilidade aparente, em bezerros holandeses alimentados com dietas contendo diferentes níveis de volumoso. In: REUNIÃO ANUAL DA SOCIEDADE BRASILEIRA DE ZOOTECNIA, 35, 1998, Botucatu, SP, Anais... Botucatu: SBZ, 1998. p. 422-424.

SILVA, D.J. 1990. Análise de alimentos (métodos químicos e biológicos). Viçosa, MG: UFV, Impr. Univ. $165 \mathrm{p}$.

SNIFFEN, C.J., O'CONNOR, J.D., VAN SOEST, P.J. et al. 1992. A net carbohydrate and protein system for evaluating cattle diets: II. carbohydrate and protein availability. J. Anim. Sci., 70(3):3562-3577. 
920 Rev. bras. zootec.

STOKES, S.R., HOOVER, W.H. MILLER, T.K. et al. 1991. Ruminal digestion and microbial utilization of diets varying in type of carbohydrate and protein. J. Dairy Sci., 74(4):871-881.

THIAGO, L.R.L.S., GILL, M. 1990. Consumo voluntário de forragens por ruminantes: mecanismo físico ou fisiológico? In: Bovinocultura de corte. Piracicaba: FEALQ. p.47-78.

UNIVERSIDADE FEDERAL DE VIÇOSA - UFV. 1994. Departamento de Engenharia Agrícola. Estação Meteorológica. In: —— Dados Climáticos. Viçosa, MG: UFV. n.p.

UNIVERSIDADE FEDERAL DE VIÇOSA - SAEG. 1995. Sistema de análises estatísticas e genética. Viçosa, MG, (Apostila).

VALADARES FILHO, S.C. Digestão total e parcial da matéria seca e carboidratos em bovinos e bubalinos. Viçosa, MG:UFV, 1985. 148 p. Tese (Doutorado em Zootecnia) - Universidade Federal de Viçosa, 1985.
VALADARES, R.F.D., GONÇALVES, L.C., SAMPAIO, I.B. et al. 1997. Níveis de proteína em dietas de bovinos. 1. Consumo e digestibilidades aparentes totais e parciais. R. Bras. Zootec., 26(6):1252-1258.

WALDO, D.R. 1986. Effect of forage quality on intake and forage-concentrate interactions. J. Dairy Sci., 69(4):617-631.

Recebido em: 12/04/99

Aceito em: 13/10/99 